\title{
Effects of the Inductive Charging on the Electrification and Lightning Discharges in Thunderstorms
}

\author{
Zheng Shi ${ }^{1}$, Hui-Qiang Tang ${ }^{2, *}$, and Yong-Bo Tan ${ }^{1}$ \\ ${ }^{1}$ Key Laboratory of Meteorological Disaster, Ministry of Education (KLME)/Joint International Research Laboratory of Climate \\ and Environment Change (ILCEC)/Collaborative Innovation Center on Forecast and Evaluation of Meteorological Disasters \\ (CIC-FEMD)/Key Laboratory for Aerosol-Cloud-Precipitation of China Meteorological Administration, \\ Nanjing University of Information Science \& Technology, Nanjing, China \\ ${ }^{2}$ Jiangsu collaborative Innovation Center on Atmospheric Environment and Equipment Technology, Nanjing, China
}

Received 21 October 2015, revised 7 December 2015, accepted 10 December 2015

\begin{abstract}
A two-dimensional cloud model with electrification and lightning processes is used to investigate the role of inductive charge separation in thunderstorm clouds. For the same dynamic and microphysical evolution, four cases that the same noninductive charging parameterization is combined with different inductive charging process are compared. Non-inductive charge separation alone is found to be sufficient to produce a dipolar charge structure. Intracloud (IC) and positive cloud-toground $(+C G)$ flashes are initiated between a main negative charge region and an upper positive charge region. The inductive charging process between graupel and cloud droplets exhibits a normal tripole charge structure, consisting of a lower positive charge region under the main negative charge region. In the simulated tripole structure, negative cloud-to-ground (-CG) flashes are initiated between the main negative and lower positive charge regions. In addition, inductive charge separation between the graupel and ice crystal is found to be capable of producing strong charge separation in a dipole charge structure. Tests with inductive graupel-ice crystals process produce more flashes than that in the other cases.
\end{abstract}

Key words: Inductive charging, Lightning discharge, Non-inductive charging, Charge structure, Numerical simulation

Citation: Shi, Z., H. Q. Tang, and Y. B. Tan, 2016: Effects of the inductive charging on the electrification and lightning discharges in thunderstorms. Terr. Atmos. Ocean. Sci., 27, 241-251, doi: 10.3319/TAO.2015.12.10.01(A)

\section{INTRODUCTION}

At present there are two primary categories of charge separation mechanisms that have been proposed to explain thunderstorm electrification: the non-inductive charging mechanism and inductive charging mechanism. The noninductive charging separation mechanism has been well examined using a host of laboratory experiments and model studies (Takahashi 1978; Jayaratne et al. 1983; Gardiner et al. 1985; Saunders et al. 1991; Ziegler et al. 1991; Saunders and Peck 1998). In addition, the comparison of laboratorybased non-inductive charging parameterizations in a full simulation model (with coupled dynamics and microphysics) has revealed significant differences between the results (Helsdon et al. 2001; Mansell et al. 2005). However, in contrast to non-inductive charging that been well understood

\footnotetext{
* Corresponding author

E-mail:thq@nuist.edu.cn
}

the influence of inductive charging on electrification and lightning discharge is highly uncertain.

Inductive charging, formed between colliding and rebounding cloud particles which are polarized by a vertical electric field, is one of a number of charging mechanisms (Aufdermaur and Johnson 1972; Jennings 1975; Sartor 1981; Mason 1988; Brooks and Saunders 1994). In addition, within the inductive charging mechanism there are two different sets of colliding and rebounding cloud particles (ice-ice and ice-drop interactions). Since most droplets will freeze onto the graupel, the charge transfer is weak. It has been suggested that there is also the possibility of ice particles rebounding which will lead to inductive charge transfer (Rawlins 1982; Helsdon et al. 1992, 2001). However, several studies suggested that electrification via inductive charging occurs only when ice particles experience rebounding collisions with cloud droplets in the presence of an electric 
filed (Ziegler et al. 1991; Mansell et al. 2005; Fierro et al. 2006, 2008; Pinty and Barthe 2008). Because contact times for ice-ice interactions are too short for electrical currents to transfer charge, the lower conductivity of ice makes polarization charging transfer ineffective (Ziegler et al. 1991; Mansell et al. 2005). Therefore, more detailed laboratory experiments dealing with the inductive process should be carried out.

Due to the lack of observations, an in-depth study of storm electrification requires numerical simulations. Several different inductive charging theories have been studied using numerical cloud models. However, many thunderstorm models have included the inductive charging process but with conflicting results (Kuettner et al. 1981; Rawlins 1982; Helsdon et al. 2001; Mansell et al. 2005; Mansell 2010; Mansell and Ziegler 2013). Because different inductive parameterizations were used in these modeling studies, we have little knowledge about the role of inductive processes in the evolution of thunderstorm electrification. For example, inductive charging between ice particles can increase the magnitude of charge separation and further strengthen the electric field in thunderstorms (Kuettner et al. 1981; Rawlins 1982; Helsdon et al. 2001). In addition, Mansell et al. (2005) stated that inductive processes with graupel-cloud droplet interaction have a great impact on the development of lower charge regions. However, as described in Mansell (2010) and Mansell and Ziegler (2013), the inductive process was not considered because it was suggested that the magnitude inductive charge separation rate was generally weaker than non-inductive charging. The impact of inductive charge separation on electrification therefore needs to be evaluated when considering the different inductive charging processes. On the other hand, as charge distributions in thunderstorms are closely related to the lightning discharge characteristics (Carey and Rutledge 1998; Coleman et al. 2003; Qie et al. 2005; Tan et al. 2006, 2012, 2014a, b), these different inductive processes perhaps have a great influence on lightning discharge.

From the above studies one can conclude that few attempts have yet been made to investigate the inductive charging effect on electrification and lightning discharge in cloud models. The objective of this study is to compare the electrification, charge distribution and lightning discharges (includes IC and CG lightning) when (1) non-inductive process is at work, (2) including non-inductive process, the inductive process operates between graupel and cloud droplets, (3) considering non-inductive process and the inductive process between graupel and ice crystals, (4) the three processes working together. For this purpose, a two-dimensional (2D) cumulus model with detailed cloud microphysics, electrification and lightning discharge scheme is used. Numerical experiments are tested mainly for the relationship between the inductive process and electrification in thunderstorms.

\section{MODEL DETAIL}

The numerical model used in this study was developed by $\mathrm{Hu}$ and $\mathrm{He}$ (1987). It is a non-hydrostatic cumulus model. As described in Shi et al. (2015), prognostic equations in this model are included for momentum, pressure, potential temperature, mixing ratio and hydrometer particle concentration, and cloud droplet spectral width, which is used to calculate the cloud droplet conversion into rain. The main cloud physical processes are activation, condensation and evaporation, collision, auto conversion, nucleation and multiplication, melting, and freezing. The model includes 28 kinds of microphysical processes. The 28 kinds of microphysical processes are: cloud condensation nuclei $(\mathrm{CCN})$ activation; ice crystal, rain, cloud droplet, graupel, and hail condensation and evaporation; collisions between cloud droplets and ice crystals, rain, graupel, as well as hail; collisions between rain and ice crystals; collisions between rain and graupel, and hail; collisions between ice crystals and graupel, and hail; nucleation and multiplication of ice crystals; auto conversions into cloud-rain, ice-graupel, and graupel-hail; freezing of rain into graupel; melting of graupel, hail, and ice into rain; collection of ice, collection of rain, and welt growth of graupel. It must be stated that the cloud droplet concentration is assumed to be constant in the original model version. Therefore, we made some improvements to the model. A background field for the initial aerosol spectrum and concentration was added to this model. We fit a classic scheme for aerosol activation based on the Köhler equation (Pruppacher and Klett 1997), and the cloud droplet activation concentration can replace the original constant (detailed can been seen in Shi et al. 2015).

For electrification, graupel-ice non-inductive collisional charging is calculated in the model. In the current study the model uses the GZ (Gardiner/Ziegler) non-inductive charging scheme (Fig. 1), which is adapted from Ziegler et al. (1991). As can been seen from Fig. 1, the sign of charge acquired by the graupel depends on the cloud water content and the ambient temperature. Based on Mansell et al. (2005), the reversal temperature $(\mathrm{Tr})$ is $-15^{\circ} \mathrm{C}$. At temperatures below $\mathrm{Tr}$, graupel (ice) charges negatively (positively) and at higher temperatures the charging sign is reversed.

Electrification via induction in the model occurs when graupel collide with cloud droplets/ice crystals. Inductive collision charging parameterization is based on Ziegler et al. (1991). The inductive grapuel-cloud droplet/ice crystal charging rate can be given by:

$$
\begin{aligned}
\left(\frac{\partial Q_{e g}}{\partial t}\right)_{p}= & \left(\pi^{3} / 8\right)\left[\frac{6.0 V_{g}}{\Gamma(4.5)}\right] E_{g c l i} E_{r c l i} N_{c l i} N_{0 g} D_{c / i}^{2} \\
& {\left[\begin{array}{l}
\pi \Gamma(3.5) \varepsilon(\cos \theta) \cos E_{z} D_{g}^{2}- \\
\Gamma(1.5) Q_{e g} /\left(3 N_{g}\right)
\end{array}\right] }
\end{aligned}
$$

Where $Q_{e g}$ is the individual charge from grapuel, $D_{c / i}$ and $D_{g}$ 
are the diameter of cloud droplets and graupel, respectively. $V_{g}$ is the falling speed of grapuel, $N_{c / i}$ and $N_{g}$ are the cloud droplet/ice crystal and graupel concentrations, respectively. $N_{o g}$ is the number concentration intercept for graupel. $\Gamma$ is the complete gamma function, and $E_{z}$ is the vertical electric field. The symbols $E_{g c / i}$ and $E_{r c / i}$ denote graupel-cloud droplet/ice crystal collision efficiency and rebound probability, respectively. $\theta$ is the polar collision angle. According to Mansell et al. (2005), coefficients for inductive graupelcloud droplet charging $\left(E_{r c}=0.01\right.$ and $\left.\cos \theta=0.4\right)$ in this study are between the moderate to strong values which range from $E_{r c}=0.007$ to 0.015 and $\cos \theta=0.2$ to 0.5 . In addition, coefficients for inductive graupel-ice crystal charging $E_{r i}=0.7$ and $\cos \theta=0.2$.

Lightning discharges are parameterized based on Tan et al. (2006, 2014a, b). Lightning initiation uses the runaway electron threshold for break-even field and thereafter bidirectional channels (with positive charge on one end and negative on the other) are propagated in a stochastic stepby-step fashion. The leaders of IC (intracloud) lightning do not reach ground, and a height threshold $(1.5 \mathrm{~km}$ or 6 grid points above ground) is used to define a flash to be a CG (cloud-to-ground) lightning (includes $+\mathrm{CG}$ and $-\mathrm{CG}$ ).

Under these conditions, a resolution of $250 \mathrm{~m}$ and time steps of 2 seconds are used to calculate the microphysical and electrification processes in the $76 \times 20 \mathrm{~km}$ domain. Thereafter, a conversion scheme from coarse to fine resolution charge distribution is used when simulating fine resolution $(25 \mathrm{~m})$ discharge processes. Since the spatial potential field and intensity are uniquely determined by the spatial charge distribution and boundary conditions, one can assign the coarse grid charge density directly to all fine resolution grids within $250 \times 250 \mathrm{~m}$ of the coarse grid. When discharge terminates, the charge density value averaged over all fine resolution grids is mapped back to the coarse grid.

\section{MODEL INITIALIZATION AND EXPERIMENT METHODOLOGY}

All simulations were carried out for $80 \mathrm{~min}$. To initiate the cloud, a temperature perturbation $(4.5 \mathrm{~K})$ and a relative humidity perturbation (80\%) were applied for one time step at $\mathrm{t}=0$ at a height of $1 \mathrm{~km}$, in the middle of the domain. Following Yin et al. (2000), the aerosol distribution was fitted by superimposing three log-normal distribution functions. The aerosol concentration decreased with height and maintained the same in the horizontal direction. The concentration can be expressed as:

$N_{a}(z)=N(Z=0) \times \exp (-z / 2)$

$N$ is the aerosol concentration on the ground. The initial aerosol concentration for this study is $100 \mathrm{~cm}^{-3}$.
A SEET (Studies of Electrical Evolution in Thunderstorms) mountain storm was simulated in this study. The SEET case was conducted in July and August of 1999 at the Langmuir Laboratory for Atmosphere Research in the mountains of central New Mexico (Coleman et al. 2003). The atmospheric sounding profiles (Fig. 2) on 31 July 1999 came from NCEP (National Centers for Environmental Prediction) grid data near the observation site. This environmental sounding has been used in related studies (Tan et al. 2006, 2014b; Tao et al. 2009) and is suitable for simulation.

Four Simulation cases were performed to conduct different inductive charging processes. The modeling arrangement is shown below:

Case 1: Only including non-inductive process.

Case 2: Including non-inductive process, the inductive process operates between graupel and cloud droplets.

Case 3: Considering non-inductive process and the inductive process between graupel and ice crystals.

Case 4: All three processes are applied.

\section{RESULTS}

\subsection{Dynamic and Microphysics Evolution}

In the towering cumulus growth stage of thunderstorm (before $30 \mathrm{~min}$ ), the updraft velocity increases rapidly with the release of latent heat from the cloud droplet (activated from aerosol particles) condensation process (see Fig. 3). The cloud water content also rises rapidly under the effect of rising updraft. At about 20 min of simulation, the maximum updraft velocity speed is $11.74 \mathrm{~m} \mathrm{~s}^{-1}$, and the maximum cloud water content is $5.62 \mathrm{~g} \mathrm{~kg}^{-1}$. The raindrop content increases significantly due to auto-conversion by cloud droplets. Meanwhile, the maximum mixing ratio and raindrop number concentration are $7.71 \mathrm{~g} \mathrm{~kg}^{-1}$ and $1.29 \times 10^{5} \mathrm{~kg}^{-1}$, respectively (see Fig. 4c).

The cloud top height reveals a maximum of about $10 \mathrm{~km}$ at about $40 \mathrm{~min}$, and the storm goes into the developing stage. Ice crystal formation starts after 25 min of simulation and increases very rapidly (see Fig. 4a). The ice crystal content is distributed mainly between $5 \mathrm{~km}\left(-20^{\circ} \mathrm{C}\right)$ and $10 \mathrm{~km}\left(-60^{\circ} \mathrm{C}\right)$ level and reaches their peak around $40 \mathrm{~min}$. Some ice crystals are initiated from vapor deposition onto ice nuclei. These ice crystals help initiate the collision coalescence between ice crystals and raindrops. Thereafter, secondary ice crystals are produced during cloud droplet graupel riming collection of cloud droplet with diameter greater than $24 \mu \mathrm{m}$. Ice crystals reach their maximum mixing ratio of $1.79 \mathrm{~g} \mathrm{~kg}^{-1}$ (the maximum number concentration is $9.97 \times 107 \mathrm{~kg}^{-1}$ ) at about $40 \mathrm{~min}$. Graupel is firstly produced by ice-graupel auto-conversion, and both the collisions between cloud droplets and graupel and collisions between raindrops and ice crystals play a signification role in the development of graupel growth. The time-height graupel mixing ratio and number concentration (Fig. 4b) show a maximum 


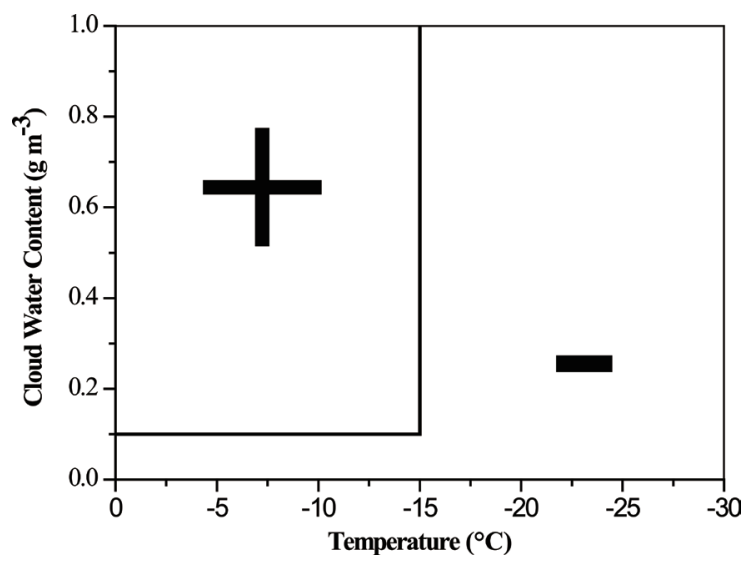

Fig. 1. Charging zones of the GZ non-inductive ice-ice parameterization (Jayaratne et al. 1983; Gardiner et al. 1985; Ziegler et al. 1991). The reversal temperature (for $\mathrm{CWC}>0.1 \mathrm{~g} \mathrm{~m}^{-3}$ ) is set at $\mathrm{Tr}=-15^{\circ} \mathrm{C}$.
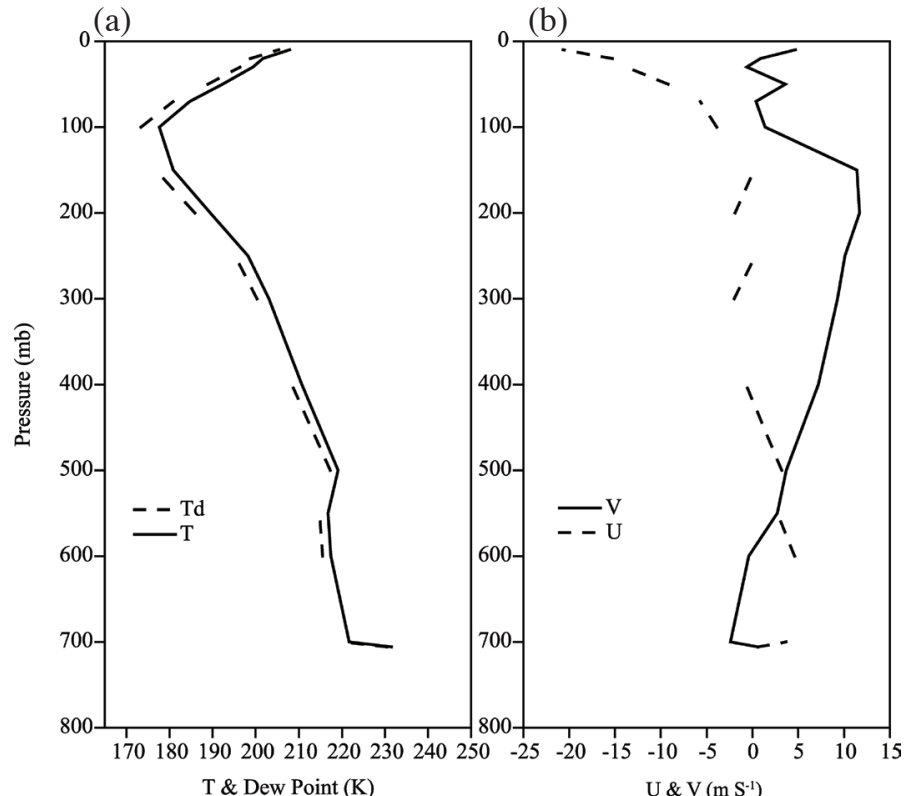

Fig. 2. Initial profiles of temperature (T), dew point (Td), and horizontal winds U and V for SEET case (Coleman et al. 2003) used in the simulation.

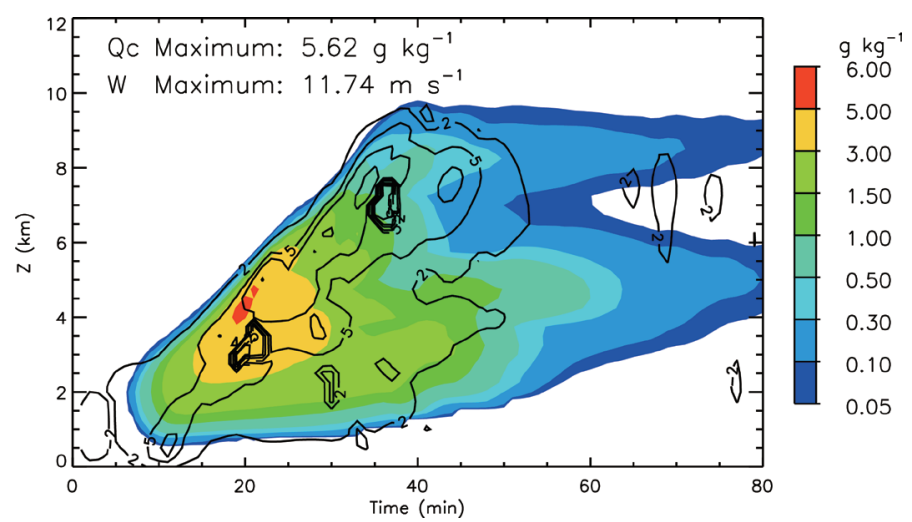

Fig. 3. The temporal evolution of space maximum mixing ratio of cloud droplets and contours of the maximum updraft with values of $2,5,7,10$, and $15 \mathrm{~m} \mathrm{~s}^{-1}$. (Color online only) 
(a)

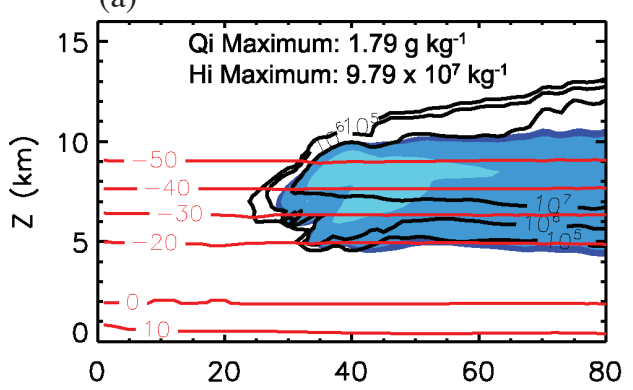

(c)

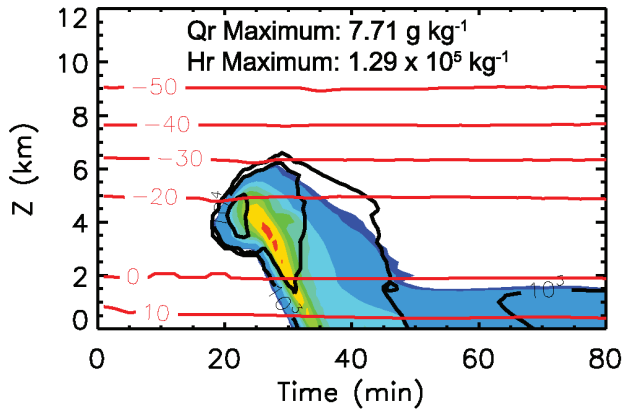

(b)

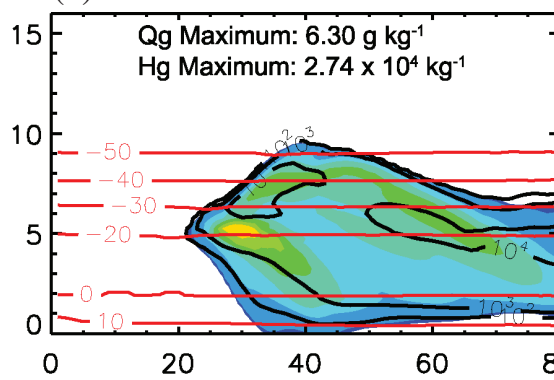

(d)

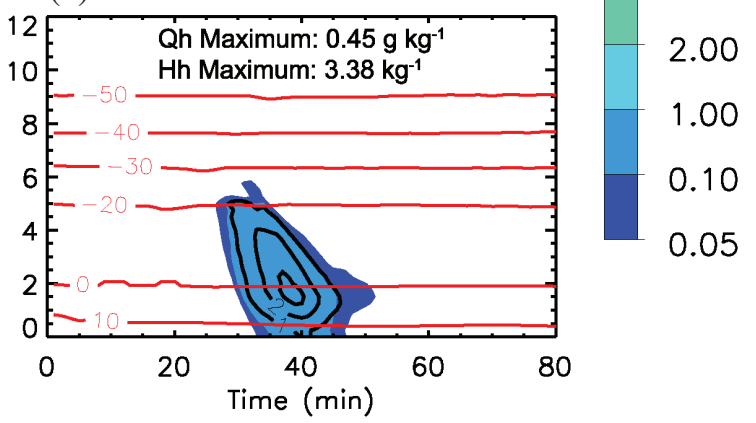

Fig. 4. Time-height plots showing the mixing ratio (shaded region) and number concentration of hydrometer particles evolution. Isotherms (thin horizontal red lines at $-50,-40,-30,-20,0$, and $10^{\circ} \mathrm{C}$ is at same in all panels. (a) Ice crystals (number concentration with contour intervals of $10^{5}$, $10^{6}, 10^{7}$, and $10^{8} \mathrm{~kg}^{-1}$ ). (b) Graupel (number concentration with contour intervals of $10^{2}, 10^{3}, 10^{4}$, and $10^{5} \mathrm{~kg}^{-1}$ ). (c) Rain (number concentration with contour intervals of $10^{3}, 10^{4}, 10^{5}$, and $\left.10^{6} \mathrm{~kg}^{-1}\right)$. (d) Hail (number concentration with contour intervals of 1, 2, 3, and $\left.4 \mathrm{~kg}^{-1}\right)$. (Color online only)

at about $33 \mathrm{~min}$, and the maximum mixing ratio and graupel number concentration is $6.30 \mathrm{~g} \mathrm{~kg}^{-1}$ and $2.74 \times 10^{4} \mathrm{~kg}^{-1}$, respectively. The raindrop content decreases due to conversion into graupel after $30 \mathrm{~min}$ but will receive compensation for collisions with cloud droplets. Meanwhile, most of the raindrops begin to move down to the height of $0^{\circ} \mathrm{C}$. During this period, because of some graupel particles experiencing the accretion of raindrops, hail particles are produced from graupel particles conversion (Fig. 4d).

In the dissipation stage (after about $50 \mathrm{~min}$ ), the updraft velocity decreases gradually with the development of precipitation particles (Fig. 3). Due to the consumption of cloud water content, the content of cloud water rapidly decreases, and thus new raindrops cannot be formed by cloud droplet auto-conversion. Raindrops then begin fall to the ground and hail and graupel begin to descend into the warm layer and melt into rain. Due to the high fall velocity and high melting rate of hail, it is easier for hail to get into the warm layer, with graupel staying longer in the cloud as it has small scale and low melting rate (Figs. $4 \mathrm{c}$ and d).

\subsection{Charging Rate}

Because the same kinematic and microphysical properties are present, only the electrification characteristic is different among the four cases. Since the non-inductive charge separated during collisions between ice-phase particles generally depends on temperature, the relative velocity of the collisions, hydrometeor concentration and the supercooled droplet size spectrum (Takahashi 1978; Jayaratne et al. 1983; Gardiner et al. 1985; Saunders et al. 1991; Brooks et al. 1997; Saunders and Peck 1998), the contributions of the non-inductive charging process to electrification in these four cases are the same. The time evolution of the non-inductive charging rate is presented in Fig. 5. Noninductive charge separation started at $25 \mathrm{~min}$ and the positive non-inductive charging rates are highest at altitudes of $3.5-8.5 \mathrm{~km}$, while the negative non-inductive charge resides mainly at $3.5-4 \mathrm{~km}$. The absolute charging rate magnitude in the positive charge region is much larger than that in the negative charge region. It is therefore clear that ice crystals from the GZ non-inductive charging scheme charge positively at lower temperatures $\left(<-15^{\circ} \mathrm{C}\right)$, and ice crystals gain a negative charge in some regions where the temperature is higher $\left(>-15^{\circ} \mathrm{C}\right)$. In addition, a large fraction of the charge separation occurs where the cloud water content (CWC) below $1 \mathrm{~g} \mathrm{~m}^{-3}$, so ice crystals predominantly obtain positive charge in the area where the CWC is lower.

The three sensitivity tests with different inductive charging processes have different inductive charging rates. A picture of the inductive charging rates is listed by the time-height plots in Fig. 6. The inductive charging rate between graupel and cloud droplets is defined as Qgc, while Qgi represents the inductive charging rate between graupel and ice crystals. Figure 6a shows that the positive or negative inductive charging rates roughly reside between $2-8 \mathrm{~km}$. The absolute 
magnitude of positive inductive charging of graupel is weak (compared to the negative inductive charging rate), but it perhaps makes a great contribution to the lower positive charge region. It can be seen from Fig. 6b that Qgi in Case 3 is much larger than Qgc in Case 2, and graupel particles obtain only negative charge during the inductive process because of the electric field vertical direction in thunderstorms remaining unchanged (the charge structure remains steady). In general, Qgi in Case 4 is roughly similar to that in Case 3 (Figs. $6 \mathrm{~b}$ and c), because of the same electric field environment in the region (4- $8 \mathrm{~km}$ ) where the initial charge is produced from non-inductive charge separation. In addition, two inductive charge separation processes combine resulting in a stronger inductive graupel-cloud droplets charging rate (Fig. 6d). This is probably because of the further increasing electric field from the inductive charging between graupel and ice crystals.

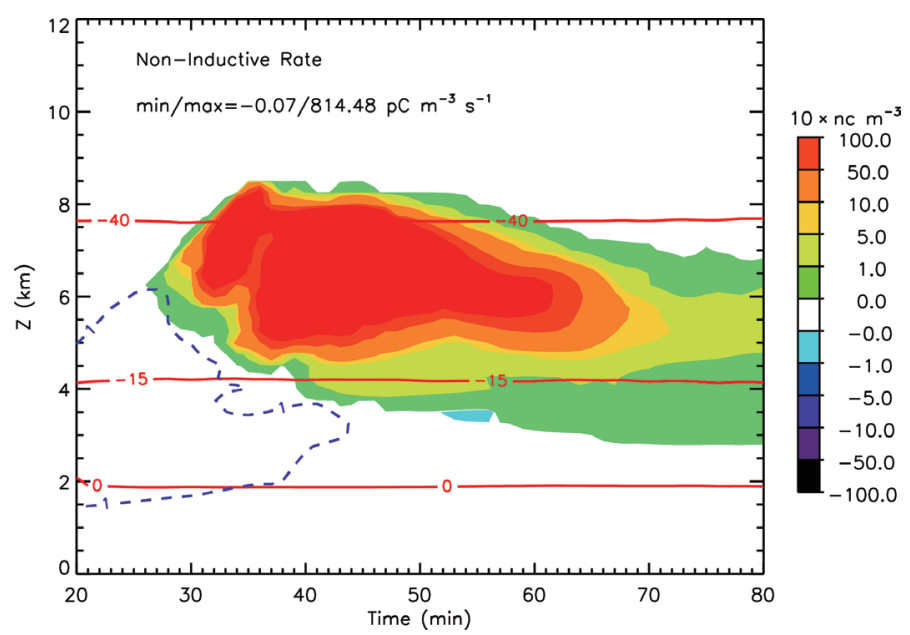

Fig. 5. Non-inductive charge separation by ice crystal per minute for four simulation cases. Isotherm (horizontal red lines at $0,-15$, and $-40^{\circ} \mathrm{C}$ ) is in the panel. The blue contour (short dashed) denotes cloud water content of $1 \mathrm{~g} \mathrm{~m}^{-3}$. (Color online only)

(a)

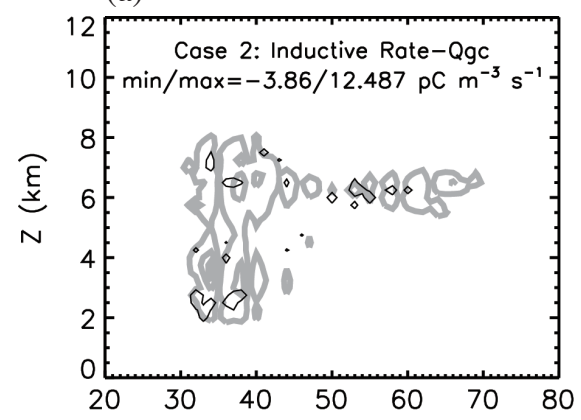

(c)

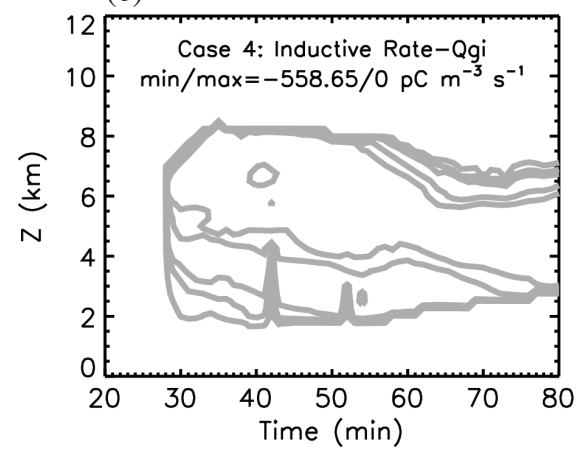

(b)

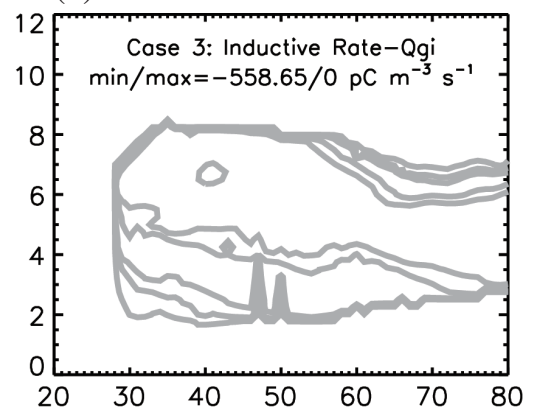

(d)

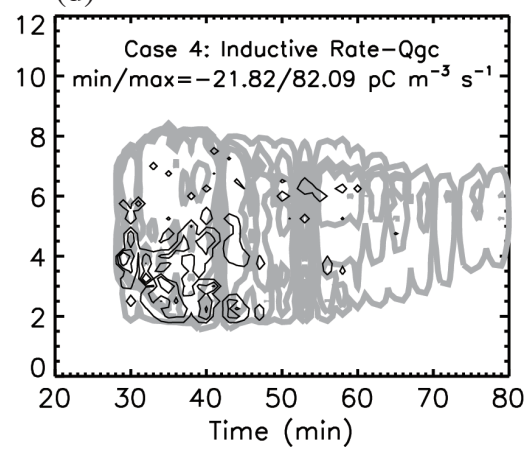

Fig. 6. Time-height plots showing the inductive charging rate evolution. (a) Inductive process between graupel and cloud droplets in Case 2; (b) inductive process between graupel and ice crystals in Case 3; (c) inductive process between graupel and ice crystals in Case 4; (d) inductive process between graupel and cloud droplets in Case 4. Positive (thin black) and negative (thick gray) inductive charging rates with contour intervals of \pm 1 , $\pm 5, \pm 10, \pm 50, \pm 100$, and $\pm 600 \mathrm{pC} \mathrm{m}^{-3} \mathrm{~s}^{-1}$. 


\subsection{Charge Structure and Lightning Discharges}

Four cases are performed for the charge structure before lightning occurs in thunderstorm clouds. The focus here is on the inductive process relevant to the charge structure in the early electrical development stage. It can be seen from Fig. 7a that the storm at 32 min depicts a normal dipole charge structure consisting of a negative charge region at $6-7.5 \mathrm{~km}$ altitude and a positive charge region above $7.5-8.5 \mathrm{~km}$. The storm charge structure at $32 \mathrm{~min}$ for Case 2 is shown in Fig. 7b. The storm has a classic triple structure with a relatively weak positive charge between $3-4 \mathrm{~km}$ (can also be called lower positive charge). This three charge layer arrangement is referred to as the 'normal tripole' (Simpson and Scrase 1937; Williams 1989). Compared to Case 1, the inductive process between graupel and cloud droplets in Case 2 contributes mainly to the lower positive charge. The storm in Case 3 also exhibits a dipole charge structure (Fig. 7c). The charge density magnitude in Case 3 is larger than that in Case 1. The vertical range of the lower negative charge region in Case 3 reaches about $6 \mathrm{~km}$, obviously greater than that in Case 1. Therefore, one can conclude that inductive charge transfer during collision between ice particles leads to stronger electrification. As both the non-inductive charge separation and inductive graupel-ice crystal charge separation in Case 3 only has an effect on enhancing the main negative and positive charge regions (see Fig. 7c), the charge structure remains a dipole. As can be seen from Fig. 7 d, Case 4 generates a normal triple, which is attributed mainly to the inductive charging between graupel and cloud droplets. Meanwhile, the charge density magnitude in Case 4 is larger than that in Case 2. This is due to the combined effect of two kinds of inductive charging processes.

As expected from the previous results the stronger charge separation is able to support more lightning activities and the charge structure characteristic exerts a substantial influence on the lightning type (Tan et al. 2014a, b). The focus here is on the dominant charge properties relevant to lightning discharges. Table 1 shows the total number of lightning flashes in four cases. Cases 3 and 4 exhibit more lightning flashes than Cases 1 and 2 and this is likely attributed to inductive charging between graupel and ice crystals producing stronger charge separation (see Table 1).

Lightning activities from four cases responding to the charge structure are shown in Fig. 8. A total of 14 lightning flashes, including 2 positive ground flashes are produced during the Case 1 simulation (Fig. 8a). The initiation points for all lightning flashes reside between $6-8 \mathrm{~km}$, between an upper positive charge region and a lower negative charge region. In the dissipation stage (about $60 \mathrm{~min}$ ), since a dipolar charge structure became closer to the ground, $+\mathrm{CG}$ flashes that composing of a negative leader traveling upward through the upper positive charge region and a positive leader traveling downward through the negative charge region to ground are prone to be generated (Fig. 8a). As can been seen in Figs. 8a and c, the two cases (Cases 1 and 3) develop similar charge distributions that can be described as a normal dipole. Under this condition, the Case 3 simulation produces
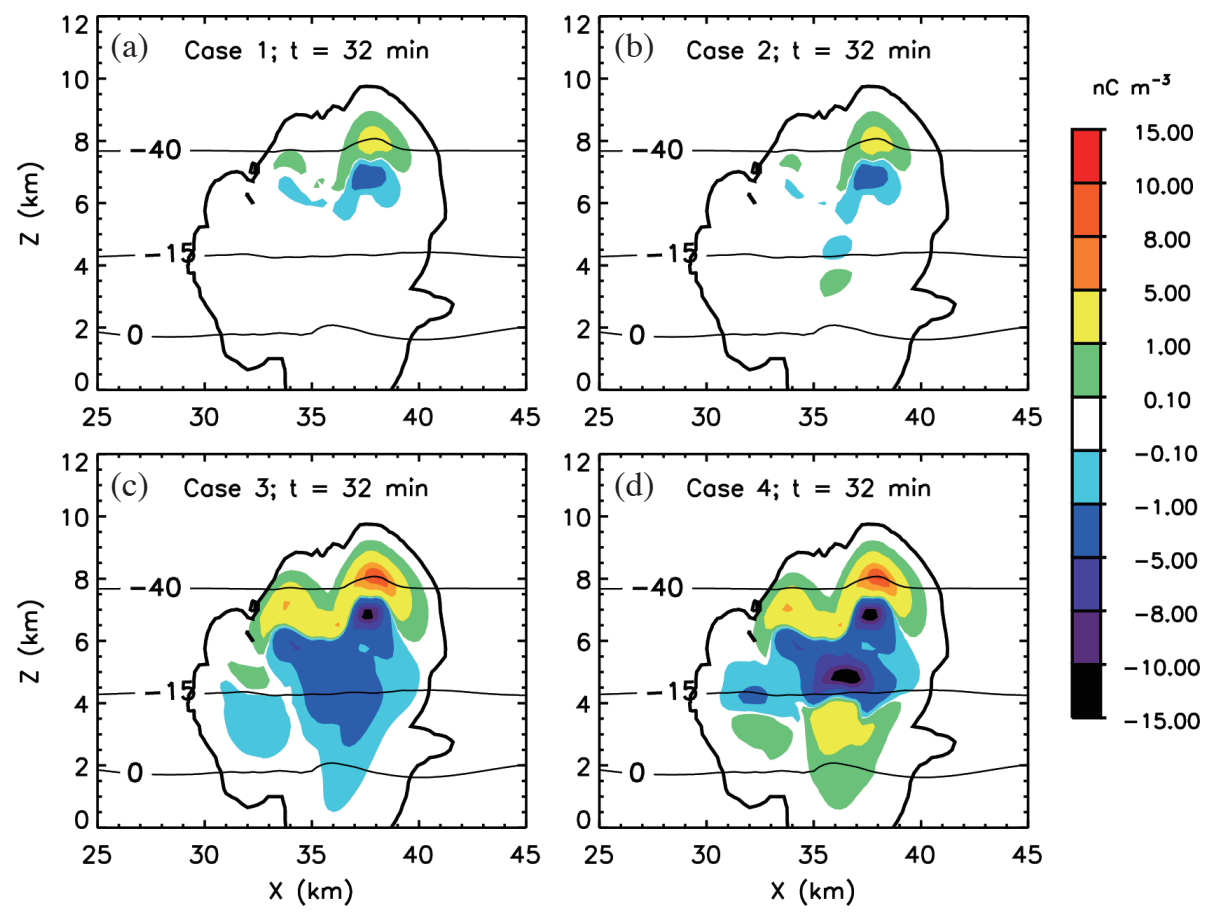

Fig. 7. Charge structure in the early electrical development stage $\left(32 \mathrm{~min}\right.$ ) for four cases. Isotherms (thin horizontal lines at $0,-15$, and $\left.-40^{\circ} \mathrm{C}\right)$ are respectively in four panels, and thick black lines show contour structure characteristics of thunderclouds. (Color online only) 
Table 1. Summary of total lightning flashes for each simulation.

\begin{tabular}{c|ccc}
\hline \multirow{2}{*}{$\begin{array}{c}\text { Charging } \\
\text { Scheme }\end{array}$} & \multicolumn{3}{|c}{ The number of flashes } \\
\cline { 2 - 4 } & IC & CG & Tot No. of flashes \\
\hline Case 1 & 12 & 2 & 14 \\
Case 2 & 10 & 7 & 17 \\
Case 3 & 19 & 9 & 28 \\
Case 4 & 13 & 17 & 30 \\
\hline
\end{tabular}
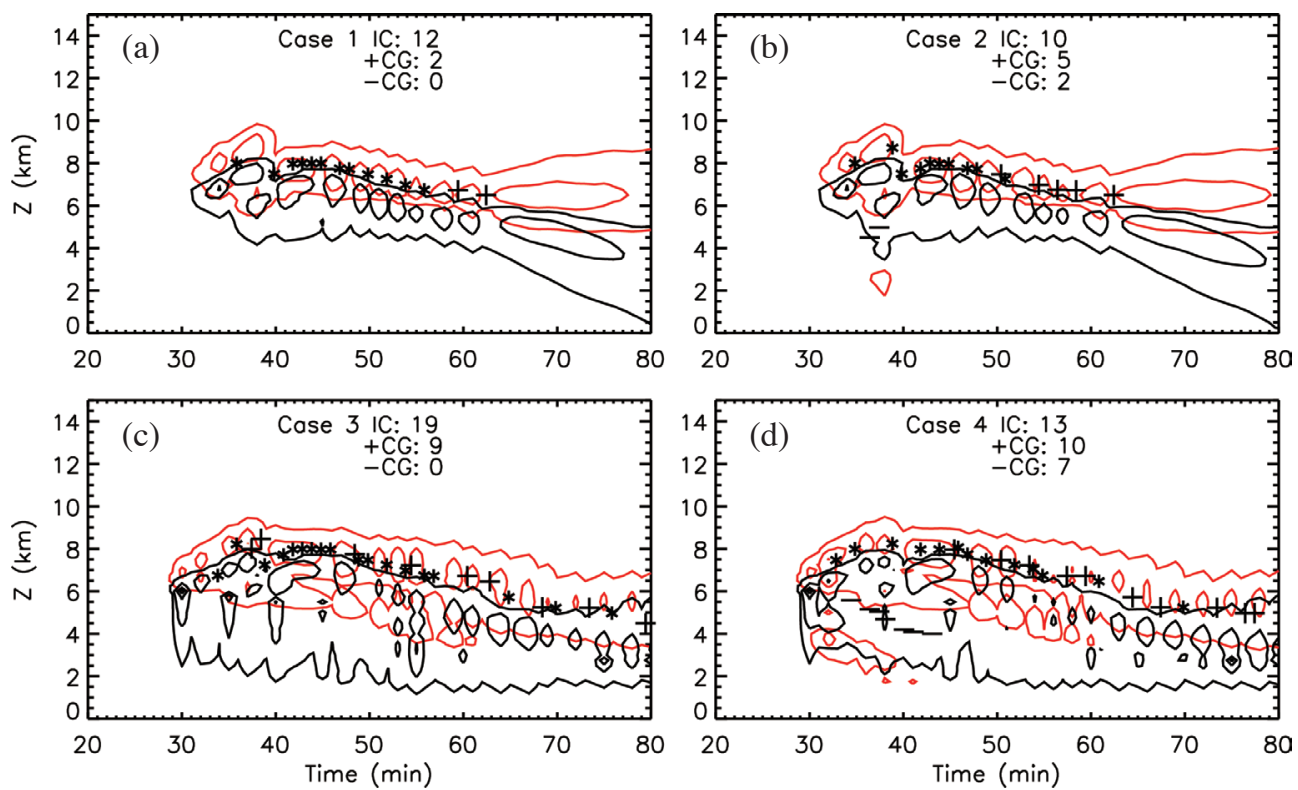

Fig. 8. Time-height maximum simulated charge separation (Contours at $\pm 0.1, \pm 1, \pm 3, \pm 5, \pm 10$, and $\pm 20 \mathrm{nC} \mathrm{m}^{-3}$, red lines denote positive charge, and black lines indicate negative charge). Lightning initiation heights are indicated by * (IC), + (+CG), - (-CG). (Color online only)

a total of 28 lightning flashes, with no negative ground flash produced. However, in Case 3, the lower negative charge region develops downward to about $2 \mathrm{~km}$ (Fig. 8c), which is favorable for a positive leader traveling downward to the ground, and thus the number of $+\mathrm{CG}$ flashes in Case 3 is greater than that in Case 1 .

Results obtained from the Case 2 and 4 simulations are comparable to the storms in Cases 1 and 3 . As shown in Figs. 8b and d, 17 total, 10 IC, $2-C G$, and $5+$ CG flashes are produced by Case 2, while Case 4 generates 30 in total, 13 IC, 7 -CG, and $10+C G$ flashes. The different lightning types are closely associated with the charge structure (Tan et al. 2014a, b). For the Case 2 and 4 simulations, these storms present a tripole structure in the $32-45$ min time range. -CG flashes occur when the lower positive charge region has sufficient charge density to cause high electric fields (Figs. 8b and d) and the negative CG lightning initiation point height is between $4-6 \mathrm{~km}$. -CG flashes begin between the main negative charge and lower positive charge, which is consistent with previous observations (Williams
1989; Pawar and Kamra 2004; Qie et al. 2005; Nag and Rakov 2009). However, Case 4 shows a stronger net positive charge region than Case 2, contributing to the initiation of more-CG flashes. In addition, the charge structure turns into a dipole in two cases after 45 min of simulation. Therefore, only $+\mathrm{CG}$ and IC can be produced during this period.

\section{CONCLUSIONS}

This study investigated the inductive charging process effect on electrification and lightning discharge using a 2D thundercloud model. In the chosen mountain storm simulation, four cases were carried out driven by different inductive charging processes. The analyses of results are concluded the following:

(1) The non-inductive charging rates are highest at altitudes of $3-8.5 \mathrm{~km}$, where the absolute charging rate magnitude in the positive charge region is much larger than that in the negative charge region. Under this condition, charge separation in Case 1 only considering the 
non-inductive charging process produce a dipolar charge structure which allows initial lightning (including IC and +CG flashes) between a main negative charge region and an upper negative charge region.

(2) The Case 3 produces more IC and +CG flashes under a dipolar charge structure as compared to Case 1. It is found that the inductive charging process between ice crystals and graupel can increase the charge production but does not alter the charge structure type.

(3) The tripolar charge structure in the developing stage is produced via inductive charge separation between graupel and cloud droplets. Cases 2 and 4 develop a lower positive charge that is involved in -CG flashes. In addition, Case 4 based on two inductive charging processes have greater lightning production than the other Cases.

Due to the limitations of the 2D model, the frequency of lightning obtained from 2D cloud model is relatively small as compared to some observations (Carey and Rutledge 1996, 1998; Lang et al. 2000; Blyth et al. 2001). The induced opposite polarity charges are deposited in the regions where the bidirectional leaders pass during a lightning discharge (following Tan et al. 2007 and Tao et al. 2009). Therefore, there is a charge re-distribution in thunderstorms. However, this impact may be much greater in the 2D model than that in the 3D model. Therefore, the charge recovery time after a lightning discharge is much longer in the $2 \mathrm{D}$ model than in the $3 \mathrm{D}$ model. This process results in a decrease in lightning production in the $2 \mathrm{D}$ model. $3 \mathrm{D}$ modeling studies will be conducted in forthcoming studies. The main objective of the present paper is to present the effect of different inductive charge separation processes on electrification and lightning discharge in thunderstorms. We believe that the results obtained using the 2D model provide an adequate description. The specific $2 \mathrm{D}$ modeling date is different from that in the 3D model, but we still believe that the inherent physical mechanisms and lightning discharge characteristics in the two model categories are similar.

Acknowledgements This work was supported by the National key foundation for exploring scientific instrument (2012YQ17003) and National Key Basic Research Program of China (973 Program) 2014CB441403 and the National Natural Science Foundation of China (Grant No. 41475006) and A Project Funded by the Priority Academic Program Development of Jiangsu Higher Education Institutions (PAPD) and Basic Research Found of Chinese Academy of Meteorological Sciences (Grant No. 2013Z006).

\section{REFERENCES}

Aufdermaur, A. N. and D. A. Johnson, 1972: Charge separation due to riming in an electric field. Q.J.R. Meteorol. Soc., 98, 369-382, doi: 10.1002/qj.49709841609. [Link]
Blyth, A. M., H. J. Christian Jr., K. Driscoll, A. M. Gadian, and J. Latham, 2001: Determination of ice precipitation rates and thunderstorm anvil ice contents from satellite observations of lightning. Atmos. Res., 59-60, 217-229, doi: 10.1016/S0169-8095(01)00117-X. [Link]

Brooks, I. M. and C. P. R. Saunders, 1994: An experimental investigation of the inductive mechanism of thunderstorm electrification. J. Geophys. Res., 99, 1062710632, doi: 10.1029/93JD01574. [Link]

Brooks, I. M, C. P. R. Saunders, R. P. Mitzeva, and S. L. Peck, 1997: The effect on thunderstorm charging of the rate of rime accretion by graupel. Atmos. Res., 43, 277295, doi: 10.1016/S0169-8095(96)00043-9. [Link]

Carey, L. D. and S. A. Rutledge, 1996: A multiparameter radar case study of the microphysical and kinematic evolution of a lightning producing storm. Meteorol. Atmos. Phys., 59, 33-64, doi: 10.1007/BF01032000. [Link]

Carey, L. D. and S. A. Rutledge, 1998: Electrical and multiparameter radar observations of a severe hailstorm. J. Geophys. Res., 103, 13979-14000, doi: 10.1029/97JD02626. [Link]

Coleman, L. M., T. C. Marshall, M. Stolzenburg, T. Hamlin, P. R. Krehbiel, W. Rison, and R. J. Thomas, 2003: Effects of charge and electrostatic potential on lightning propagation. J. Geophys. Res., 108, doi: 10.1029/2002JD002718. [Link]

Fierro, A. O., M. S. Gilmore, E. R. Mansell, L. J. Wicker, and J. M. Straka, 2006: Electrification and lightning in an idealized boundary-crossing supercell simulation of 2 June 1995. Mon. Weather Rev., 134, 3149-3172, doi: 10.1175/MWR3231.1. [Link]

Fierro, A. O., L. M. Leslie, E. R. Mansell, and J. M. Straka, 2008: Numerical simulations of the microphysics and electrification of the weakly electrified 9 February 1993 TOGA COARE squall line: Comparisons with observations. Mon. Weather Rev., 136, 364-379, doi: 10.1175/2007MWR2156.1. [Link]

Gardiner, B., D. Lamb, R. L. Pitter, J. Hallett, and C. P. R. Saunders, 1985: Measurements of initial potential gradient and particle charges in a Montana summer thunderstorm. J. Geophys. Res., 90, 6079-6086, doi: 10.1029/JD090iD04p06079. [Link]

Helsdon, J. H., Jr., G. Wu, and R. D. Farley, 1992: An intracloud lightning parameterization scheme for a storm electrification model. J. Geophys. Res., 97, 5865-5884, doi: 10.1029/92JD00077. [Link]

Helsdon, J. H., Jr., W. A. Wojcik, and R. D. Farley, 2001: An examination of thunderstorm-charging mechanisms using a two-dimensional storm electrification model. J. Geophys. Res., 106, 1165-1192, doi: 10.1029/2000JD900532. [Link]

Hu, Z. and G. He, 1987: Numerical simulation of microprocesses in cumulonimbus clouds (I) microphysical model. Acta Meteorol. Sin., 45, 467-484, doi: 10.11676/ 
qxxb1987.060. (in Chinese) [Link]

Jayaratne, E. R., C. P. R. Saunders, and J. Hallett, 1983: Laboratory studies of the charging of soft-hail during ice crystal interactions. Q. J. R. Meteorol. Soc., 109, 609-630, doi: 10.1002/qj.49710946111. [Link]

Jennings, S. G., 1975: Electrical charging of water drops in polarizing electric fields. J. Electrostat., 1, 15-25, doi: 10.1016/0304-3886(75)90004-2. [Link]

Kuettner, J. P., Z. Levin, and J. D. Sartor, 1981: Thunderstorm electrification--Inductive or non-inductive? $J$. Atmos. Sci., 38, 2470-2484, doi: 10.1175/1520-0469(1981)038\%3C2470:TEONI\%3E2.0.CO;2. [Link]

Lang, T. J., S. A. Rutledge, J. E. Dye, M. Venticinque, P. Laroche, and E. Defer, 2000: Anomalously low negative cloud-to-ground lightning flash rates in intense convective storms observed during STERAO-A. Mon. Weather Rev., 128, 160-173, doi: 10.1175/1520-0493(2000)128\%3C0160:ALNCTG\%3E2.0.CO;2. [Link]

Mansell, E. R., 2010: On sedimentation and advection in multimoment bulk microphysics. J. Atmos. Sci., 67, 3084-3094, doi: 10.1175/2010JAS3341.1. [Link]

Mansell, E. R. and C. L. Ziegler, 2013: Aerosol effects on simulated storm electrification and precipitation in a two-moment bulk microphysics model. J. Atmos. Sci., 70, 2032-2050, doi: 10.1175/JAS-D-12-0264.1. [Link]

Mansell, E. R., D. R. Macgorman, C. L. Ziegler, and J. M. Straka, 2005: Charge structure and lightning sensitivity in a simulated multicell thunderstorm. J. Geophys. Res., 110, D12101, doi: 10.1029/2004JD005287. [Link]

Mason, J., 1988: The generation of electric charges and fields in thunderstorms. Proc. Math. Phys. Eng. Sci., 415, 303-315, doi: 10.1098/rspa.1988.0015. [Link]

Nag, A. and V. A. Rakov, 2009: Some inferences on the role of lower positive charge region in facilitating different types of lightning. Geophys. Res. Lett., 36, L05815, doi: 10.1029/2008GL036783. [Link]

Pawar, S. D. and A. K. Kamra, 2004: Evolution of lightning and the possible initiation/triggering of lightning discharges by the lower positive charge center in an isolated thundercloud in the tropics. J. Geophys. Res., 109, D02205, doi: 10.1029/2003JD003735. [Link]

Pinty, J. P. and C. Barthe, 2008: Ensemble simulation of the lightning flash variability in a $3 \mathrm{D}$ cloud model with parameterizations of cloud electrification and lightning flashes. Mon. Weather Rev., 136, 380-387, doi: 10.1175/2007MWR2186.1. [Link]

Pruppacher, H. R. and J. D. Klett, 1997: Microphysics of Clouds and Precipitation, Second Revised and Enlarged Edition with an Introduction to Cloud Chemistry and Cloud Electricity, Kluwer Academic Publishers, Dordrecht, $954 \mathrm{pp}$.

Qie, X., T.Zhang, C. Chen, G. Zhang, T.Zhang, and W. Wei, 2005: The lower positive charge center and its effect on lightning discharges on the Tibetan Plateau. Geophys.
Res. Lett., 32, L05814, doi: 10.1029/2004GL022162. [Link]

Rawlins, F., 1982: A numerical study of thunderstorm electrification using a three dimensional model incorporating the ice phase. Q. J. R. Meteorol. Soc., 108, 779800, doi: 10.1002/qj.49710845804. [Link]

Sartor, J. D., 1981: Induction charging of clouds. J. Atmos. Sci., 38, 218-220, doi: 10.1175/1520-0469(1981)038\%3C0218:ICOC\%3E2.0.CO;2. [Link]

Saunders, C.P. R. and S. L. Peck, 1998: Laboratory studies of the influence of the rime accretion rate on charge transfer during crystal/graupel collisions. J. Geophys. Res., 103, 13949-13956, doi: 10.1029/97JD02644. [Link]

Saunders, C.P.R., W.D. Keith, and R.P. Mitzeva, 1991: The effect of liquid water on thunderstorm charging. J. Geophys. Res., 96, 11007-11017, doi: 10.1029/91JD00970. [Link]

Shi, Z., Y. B. Tan, H. Q. Tang, J. Sun, Y. Yang, L. Peng, and X. F. Guo, 2015: Aerosol effect on the land-ocean contrast in thunderstorm electrification and lightning frequency. Atmos. Res., 164-165, 131-141, doi: 10.1016/j. atmosres.2015.05.006. [Link]

Simpson, G. and F. J. Scrase, 1937: The distribution of electricity in thunderclouds. Proc. Math. Phys. Eng. Sci., 161, 309-352, doi: 10.1098/rspa.1937.0148. [Link]

Takahashi, T., 1978: Riming electrification as a charge generation mechanism in thunderstorms. J. Atmos. Sci., 35, 1536-1548, doi: 10.1175/1520-0469(1978)035\%3 C1536:REAACG\%3E2.0.CO;2. [Link]

Tan, Y. B., S. Tao, and B. Zhu, 2006: Fine-resolution simulation of the channel structures and propagation features of intracloud lightning. Geophys. Res. Lett., 33, L09809, doi: 10.1029/2005GL025523. [Link]

Tan, Y. B., S. C. Tao, B. Y. Zhu, M. Ma, and W. T. Lü, 2007: A simulation of the effects of intra-cloud lightning discharges on the charges and electrostatic potential distributions in a thundercloud. Chin. J. Geophys., 50, 916-930, doi: 10.1002/cjg2.1109. [Link]

Tan, Y. B., Z. Shi, N. N. Wang, and X. F. Guo, 2012: Numerical simulation of the effects of randomness and characteristics of electrical environment on ground strike location of cloud-to-ground lightning. Chin. J. Geophys., 55, 626-634, doi: 10.1002/cjg2.1757. [Link]

Tan, Y. B., Z. W. Liang, Z. Shi, J. R. Zhu, and X. F. Guo, 2014a: Numerical simulation of the effect of lower positive charge region in thunderstorms on different types of lightning. Sci. China Earth Sci., 57, 2125-2134, doi: 10.1007/s11430-014-4867-7. [Link]

Tan, Y. B., S. Tao, Z. W. Liang, and B. Zhu, 2014b: Numerical study on relationship between lightning types and distribution of space charge and electric potential. J. Geophys. Res., 119, 1003-1014, doi: 10.1002/2013JD019983. [Link]

Tao, S., Y. Tan, B. Zhu, M. Ma, and W. Lu, 2009: 
Fine-resolution simulation of cloud-to-ground lightning and thundercloud charge transfer. Atmos. Res., 91, 360370, doi: 10.1016/j.atmosres.2008.05.012. [Link]

Williams, E. R, 1989: The tripole structure of thunderstorms. J. Geophys. Res., 94, 13151-13167, doi: 10.1029/ JD094iD11p13151. [Link]

Yin, Y., Z. Levin, T. G. Reisin, and S. Tzivion, 2000: The effects of giant cloud condensation nuclei on the de- velopment of precipitation in convective clouds--A numerical study. Atmos. Res., 53, 91-116, doi: 10.1016/ S0169-8095(99)00046-0. [Link]

Ziegler, C. L., D. R. Macgorman, J. E. Dye, and P. S. Ray, 1991: A model evaluation of noninductive graupelice charging in the early electrification of a mountain thunderstorm. J. Geophys. Res., 96, 12833-12855, doi: 10.1029/91JD01246. [Link] 